\title{
Changes to the North Atlantic Subtropical High and Its Role in the Intensification of Summer Rainfall Variability in the Southeastern United States
}

\author{
WENHONG LI AND LAIFANG LI \\ Earth and Ocean Sciences, Nicholas School, Duke University, Durham, North Carolina \\ RONG FU \\ Department of Geological Sciences, University of Texas at Austin, Austin, Texas \\ YI DENG \\ Earth and Atmospheric Sciences, Georgia Institute of Technology, Atlanta, Georgia \\ HUI WANG \\ NCEP/NWS/NOAA/Climate Prediction Center, Camp Springs, Maryland, and Wyle Information Systems, \\ McLean, Virginia
}

(Manuscript received 5 May 2010, in final form 6 October 2010)

\begin{abstract}
This study investigates the changes of the North Atlantic subtropical high (NASH) and its impact on summer precipitation over the southeastern (SE) United States using the 850-hPa geopotential height field in the National Centers for Environmental Prediction (NCEP) reanalysis, the 40-yr European Centre for Medium-Range Weather Forecasts (ECMWF) Re-Analysis (ERA-40), long-term rainfall data, and Intergovernmental Panel on Climate Change (IPCC) Fourth Assessment Report (AR4) model simulations during the past six decades (1948-2007). The results show that the NASH in the last 30 yr has become more intense, and its western ridge has displaced westward with an enhanced meridional movement compared to the previous $30 \mathrm{yr}$. When the NASH moved closer to the continental United States in the three most recent decades, the effect of the NASH on the interannual variation of SE U.S. precipitation is enhanced through the ridge's north-south movement. The study's attribution analysis suggested that the changes of the NASH are mainly due to anthropogenic warming. In the twenty-first century with an increase of the atmospheric $\mathrm{CO}_{2}$ concentration, the center of the NASH would be intensified and the western ridge of the NASH would shift farther westward. These changes would increase the likelihood of both strong anomalously wet and dry summers over the SE United States in the future, as suggested by the IPCC AR4 models.
\end{abstract}

\section{Introduction}

Summer precipitation over the southeastern (SE) United States is important for regional hydrology and agriculture. In recent decades (1948-2007), observations have shown intensified year-to-year fluctuations in summer rainfall over this region (Wang et al. 2010). During the boreal summer [June-August (JJA)], the frequency of summers with strongly anomalous precipitation, defined

Corresponding author address: Dr.Wenhong Li, Earth and Ocean Sciences, Nicholas School of the Environment, Duke University, 321C Old Chem Bldg, P.O. Box 90227, Durham, NC 27708. E-mail: wenhong.li@duke.edu as summers with total seasonal precipitation anomalies greater than one standard deviation, has more than doubled in the second $30 \mathrm{yr}$ of this period compared to the first $30 \mathrm{yr}$ (Fig. 1). This change is mainly caused by a significant increase in non rainy days during anomalously dry summers and an increase in heavy rainfall events during the anomalously wet summers (Wang et al. 2010). Chisquare tests suggest that the change in the number of summers with strongly anomalous rainfall between the two periods is significant. Compared to changes in the annual mean, strong summer rainfall anomalies have far more impact on human and natural systems (Wehner 2004). Increased drought and more intense thunderstorms have been shown to alter runoff, increase soil 


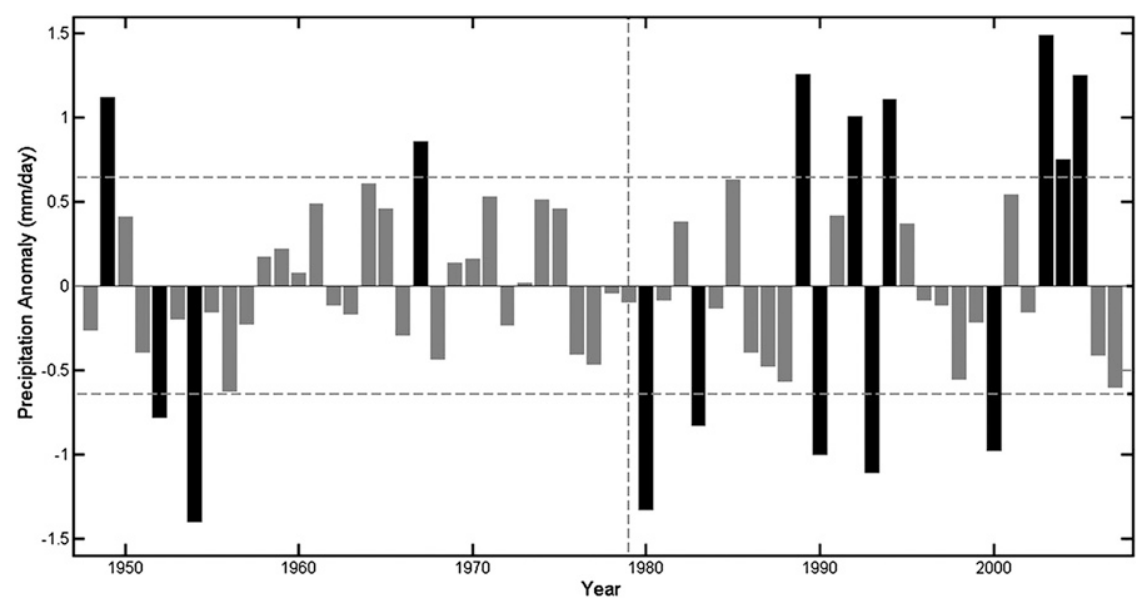

FIG. 1. Observed JJA precipitation anomaly over the SE United States for a 60 -yr period $\left(\mathrm{mm} \mathrm{day}{ }^{-1}\right)$. Horizontal dashed lines represent 1 standard deviation of the summer rainfall.

erosion, and affect crop yields across the United States (Riha et al. 1996).

Many factors could influence summer precipitation variability in the SE United States, such as sea surface temperatures (SSTs) and associated atmospheric circulation anomalies (Wang and Enfield 2001; Seager et al. 2003; Schubert et al. 2009; Kushnir et al. 2010), hurricane activities (Elsner and Tsonis 1993; Chan and Misra 2010), and soil moisture (Koster et al. 2004; Wu et al. 2007). Among them, the subtropical high over the North Atlantic is probably one of the most important contributors to the variability in the SE U.S. precipitation (Katz et al. 2003).

This subtropical high is a semipermanent system over the North Atlantic. During boreal summer, its surface center is located near Bermuda within an area bounded by $\left(25^{\circ}-40^{\circ} \mathrm{N}, 20^{\circ}-50^{\circ} \mathrm{W}\right)$ and is commonly referred to as the "Bermuda high" (Zishka and Smith 1980; Davis et al. 1997). In the past, the North Atlantic subtropical high (NASH) has been studied to improve prediction of hurricane tracks (e.g., Liu and Fearn 2000) and to understand weather and climate over the eastern United States, western Europe, and northwestern Africa (Davis et al. 1997; Kushnir et al. 2010). However, unlike the subtropical high over the Pacific (e.g., Sui et al. 2007), the impact of the interannual-to-decadal-scale variations of the subtropical high over the North Atlantic, and especially its western ridge, on the summer rainfall variability over the SE United States has not been investigated. In this study, we investigate the impact of the NASH on summer rainfall over the SE United States on interannual and decadal scales, using the National Centers for Environmental Prediction (NCEP)-National Center for Atmospheric Research (hereafter referred to as the NCEP) reanalysis data, the 40-yr European Centre for Medium-Range Weather Forecasts (ECMWF) Re-Analysis (ERA-40) dataset, long-term rainfall data, and the climate models that participated in the Intergovernmental Panel on Climate Change (IPCC) Fourth Assessment Report (AR4). In the following section, the data and primary methods are described. The definition of the NASH's intensity and movement is also discussed. Section 3 gives the results, and the conclusions and discussion are given in section 4 .

\section{Data and methods}

The data used in this study consist of precipitation, the atmospheric geopotential height, wind, and humidity fields. Summer seasonal means are obtained by averaging over JJA. To be consistent with our previous work (Wang et al. 2010), we analyzed the precipitation data from the National Oceanic and Atmospheric Administration (NOAA) Climate Prediction Center (CPC) U.S. Unified Precipitation for 1948-98 and from the real-time U.S. Daily Precipitation Analysis for 1999-2007 in the same area $\left(25^{\circ}-36.5^{\circ} \mathrm{N}, 76^{\circ}-91^{\circ} \mathrm{W}\right)$ as in Wang et al. (2010). Both datasets are on a $0.25^{\circ} \times 0.25^{\circ}$ (latitude $\times$ longitude) grid.

The 850-hPa geopotential height was chosen instead of sea level pressure to characterize the NASH in this study to avoid possible topographic effect on the west edge of the $\mathrm{NASH}$ because the semipermanent NASH has a barotropic structure below $600 \mathrm{hPa}$ (not shown). NCEP reanalysis data were analyzed from 1948-2007 (Kalnay et al. 1996), the same period of observed precipitation as in Wang et al. (2010). We also analyzed ERA-40 reanalysis for the period of 1958 to 2002 (Uppala et al. 2005) to verify our results obtained from NCEP. These are the two widely used reanalysis products with relatively long periods (60 yr for NCEP and $45 \mathrm{yr}$ for ERA-40) and have shown a consistency with previous observation to study decadal variability over the North Atlantic (Wu and Liu 2005). 
We have examined the $850-\mathrm{hPa}$ geopotential field from the coupled ocean-atmospheric general circulation models organized and coordinated by the World Climate Research Group (WCRP) Working Group on Coupled Modeling (WGCM) for the IPCC AR4 that is available at the Program for Climate Model Diagnosis and Intercomparison (PCMDI). We considered three sets of the simulations: preindustrial runs (PICNTRL), twentieth-century forced runs (20C3M), and the twenty-firstcentury simulations under the emission scenario A1B (A1B). The PICNTRL experiments represent the natural variability of a coupled ocean and atmosphere climate system with greenhouse gases fixed at the pre-industry level. The forced experiments for the twentieth century $(20 \mathrm{C} 3 \mathrm{M})$ are driven by estimated changes in a variety of anthropogenic forcings and, for some models, the changes in natural external forcings such as solar irradiance variation and volcanic aerosols. The A1B scenario describes a future world of very rapid economic growth and global population that peaks in the midcentury and declines thereafter, and it describes the rapid introduction of new and more efficient technologies (Nakicenovic et al. 2000). The $\mathrm{CO}_{2}$ concentration doubles to $720 \mathrm{ppm}$ in 2100 at the twenty-first-century simulations, after which it is fixed. There are 23 models in the pre-industry controlled run, the twentieth-century forced runs, and the twenty-firstcentury simulations.

The center of the NASH is defined as the location with the highest geopotential height at $850 \mathrm{hPa}$ within the climatological mean area $\left(20^{\circ}-45^{\circ} \mathrm{N}, 80^{\circ}-10^{\circ} \mathrm{W}\right)$ of the NASH (Davis et al. 1997); the highest geopotential height value is thus defined as the NASH's intensity. The comparison between using the domain-averaged geopotential height value over the region $\left(20^{\circ}-45^{\circ} \mathrm{N}, 80^{\circ}-10^{\circ} \mathrm{W}\right)$ and using the highest geopotential height value to represent the NASH's intensity showed similar results for our purpose. The location of the $850-\mathrm{hPa}$ center has a similar latitude and longitude to the center of the NASH at the sea level during the 60-yr period (not shown). The ridge line of the NASH is defined as a roughly zonal line north of which the trade winds reverse to westerly, thus satisfying $u=0$ and $\partial u / \partial y>0$, where $u$ is the zonal wind (Liu and Wu 2004). Traditionally, meteorologists plot geopotential height at a 20-gpm interval on $850 \mathrm{hPa}$. The 1540-gpm line is far into the continent while the 1580-gpm line is still over the North Atlantic; therefore, the1560-gpm line was used to represent the western boundary of the migration of the NASH. The summer western ridge is subsequently identified as the point where the 1560-gpm line intersects the ridge line of the NASH. To avoid the possible spread of the western ridge among the phase 3 Coupled Model Intercomparison Project (CMIP3) models and to make results comparable, we used the climatological contour straddling the longitude of $86^{\circ} \mathrm{W}$ to represent the western edge of the NASH similar to that in Zhou et al. (2009). This longitude is derived according to observed climatological NASH location based on the NCEP reanalysis data. To identify how changes of the NASH are linked to natural decadal variabilities, indices for the Atlantic multidecadal oscillation (AMO) and the Pacific decadal oscillation (PDO) are considered. AMO and PDO indices are available online from http://www.esrl.noaa.gov/psd/data/ climateindices/list/. Our work investigates the relationship between the changes of the NASH and the intensification of summer precipitation variability over the SE United States in recent decades and its implications for the future climate over the region.

\section{Results}

Both NCEP and ERA-40 reanalyses suggest a decadalscale shift of the NASH (Fig. 2). Figure 2 shows a remarkable difference in the position of the western extension of the NASH between the 1948-77 and 1978-2007 periods for NCEP and between the 1958-77 and 1978-2002 periods for ERA-40. During the first period (1948-77 for NCEP, 1958-77 for ERA-40), the mean position of the western ridge of the NASH was located at $81^{\circ} \mathrm{W}\left(82^{\circ} \mathrm{W}\right)$ in the NCEP (ERA-40) reanalysis, where in the second period (1978-07 for NCEP, 1978-02 for ERA-40), the mean western ridge shifted to $87^{\circ} \mathrm{W}\left(86^{\circ} \mathrm{W}\right)$ in NCEP (ERA-40) reanalysis (Fig. 2). There are some discrepancies between the two reanalysis datasets. The decadal shift of the western ridge is about $6^{\circ}(60 \mathrm{yr})$ in the NCEP and $5^{\circ}$ (45 yr) in ERA-40 (Fig. 2). However, both datasets indicate a significant westward trend of the western ridge of the NASH since the late 1970s (Fig. 3), similar to the results of the subtropical high over the western Pacific (Zhou et al. 2009). For NCEP and ERA-40 reanalysis data, the ridge moved westward at an average speed of $-1.22^{\circ}$ decade $^{-1}$ and $-1.19^{\circ}$ decade $^{-1}$ at the $1 \%$ and $5 \%$ significance levels, respectively, during the entire periods. In addition, both NCEP and ERA-40 reanalysis data demonstrate that the intensity of the NASH center increased at a trend of $0.9 \mathrm{gpm}$ decade $^{-1}$ and $0.87 \mathrm{gpm}$ decade $^{-1}$ at the $5 \%$ and $30 \%$ significance level during the 60- and 45-yr period, respectively. The correlation coefficient between the center's intensity and the western ridge's longitude is the $-0.42(-0.34)$ at the $1 \%(1 \%)$ significance level for NCEP (ERA-40) reanalysis data. The intensity variation of the NASH's center appears to explain $38 \%$ of the westward extension of the ridge based on linear regression (not shown). Thus, the westward extension of the ridge is closely related to the intensity change of the NASH.

With the westward extension of the NASH, the northsouth $(\mathrm{N}-\mathrm{S})$ migration of its western ridge has had a 

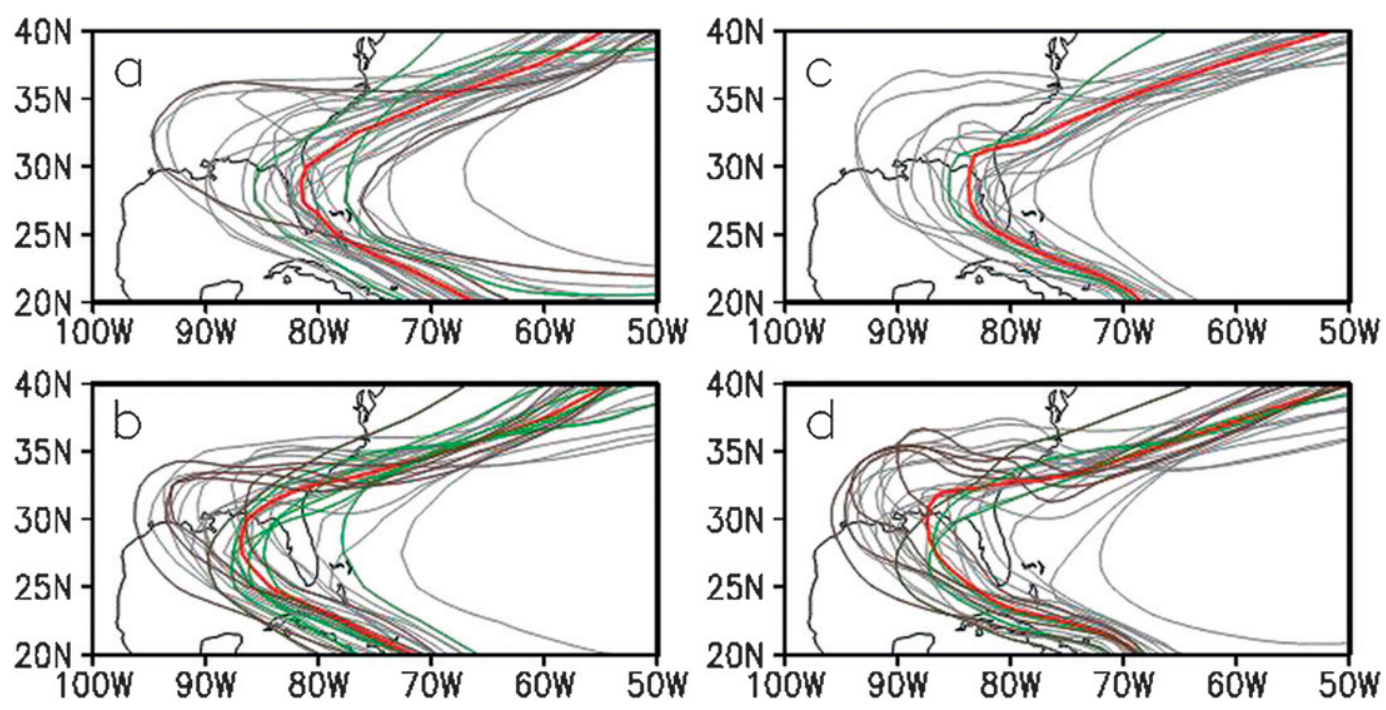

FIG. 2. Interannual variations of 1560-gpm contour line at $850 \mathrm{hPa}$ during JJA in both NCEP and ERA-40 reanalysis data for the two periods considered. (a) NCEP first period 1948-77; (b) NCEP second period 1978-2007; (c) ERA-40 first period 1958-77; and (d) ERA-40 second period 1978-2002. Red thick curves represent the mean location of the NASH in JJA for the two periods, and green and brown lines represent the NASH in wet and dry years, respectively. Note ERA-40 only covers the period 1958-2002, thus the two periods considered are 1958-77 and 1978-2002 to be in agreement with the two periods considered for the NCEP reanalysis data.

greater impact on the summer precipitation over the SE United States. Figure 4 shows the time series of the 30-yr (20-yr) moving correlation coefficient between the latitudinal variation of the western ridge using NCEP (ERA-40) and the normalized precipitation index (NPI) over the SE United States. NPI is defined as rainfall anomaly (Fig. 1) divided by its standard deviation (Wang et al. 2010). As more years from the second period are factored into the calculation, the correlation coefficient increases to about 0.7 for both NCEP and ERA-40, indicating a larger impact of the NASH on the SE U.S. summer precipitation during the second period.

The impact of latitudinal variation of the west ridge on the SE U.S. rainfall can also be seen in Fig. 5, which shows the linear regression coefficient of rainfall against the latitude of western ridge during the two periods using NCEP and ERA-40, respectively. Significant negative coefficients (less than -0.3 at the $5 \%$ significance level) are

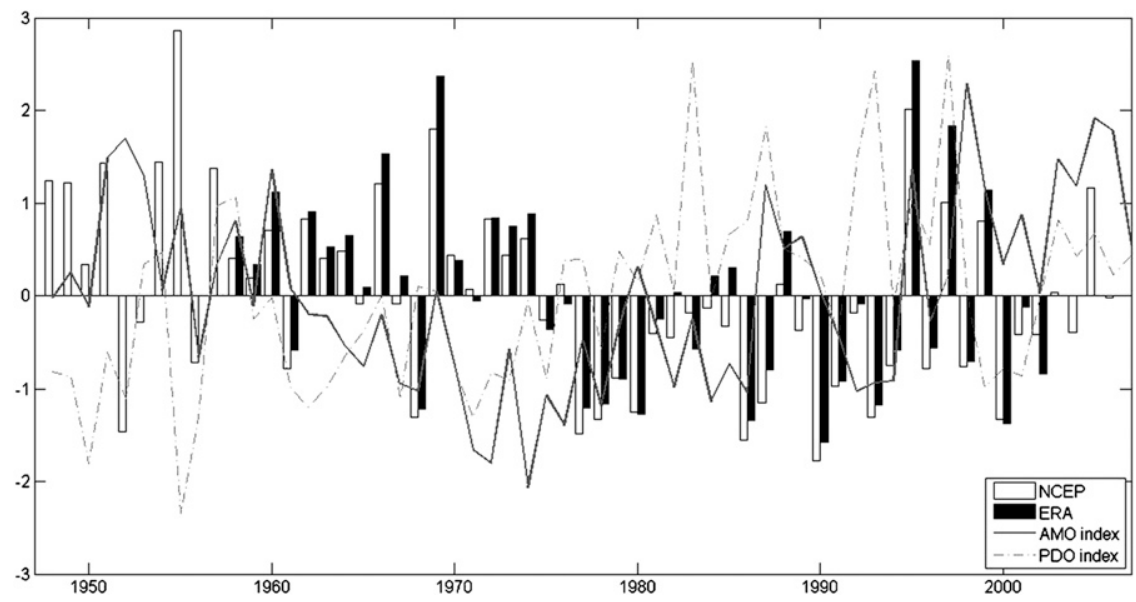

FIG. 3. West-east movement of the western ridge of the summer NASH at $850 \mathrm{mb}$ in NCEP (blue bar, unit: degree) and ERA-40 (red bar, unit: degree) reanalysis datasets, relative to their climatological mean longitude. Summer AMO (solid curve) and PDO (dashed curve) indices are also plotted. 


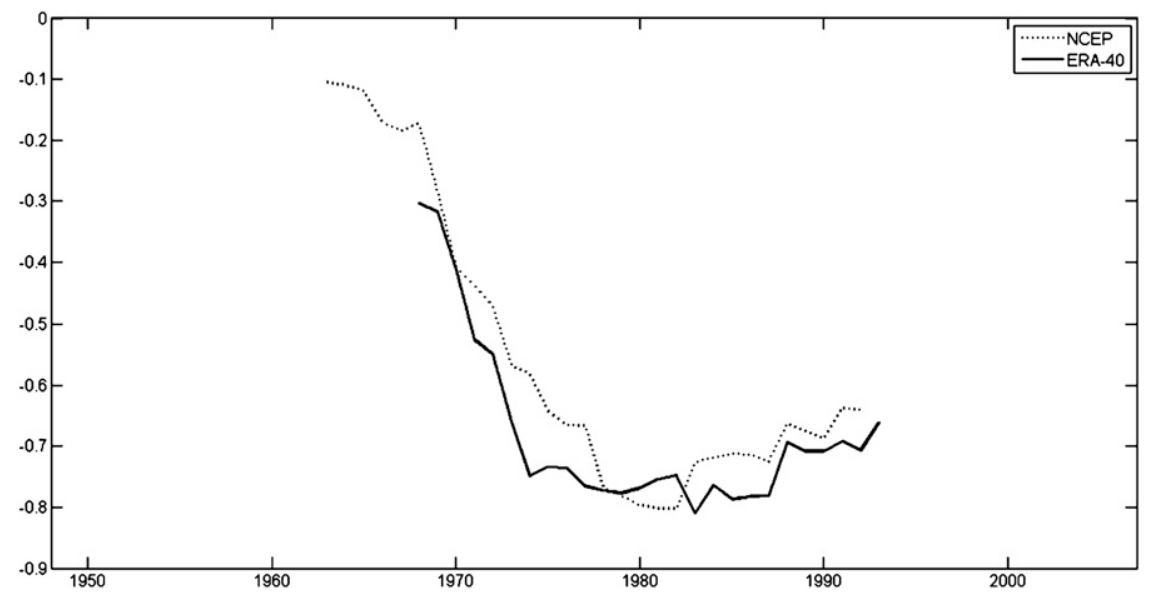

FIG. 4. The 30-yr (20-yr) moving correlation between the NPI and the latitude of the NASH west ridge endpoint in the NCEP (ERA-40) data. NPI is defined as rainfall anomaly divided by its standard deviation (Wang et al. 2010).

found in the SE United States except some parts of Florida in the second 30-yr (25-yr) period for NCEP (ERA-40; Figs. $5 \mathrm{~b}$ and $5 \mathrm{~d}$ ). Moisture fluxes for the two periods plotted in Fig. 5 also suggested the stronger influence of the NASH on the climate over the SE United States in the second period. When the western ridge moves to the north, rainfall tends to decrease in the SE United States because this region is located within the western part of the NASH and the weather pattern is dominated by subsidence (Fig. 2). Likewise, when the NASH shifts southward, rainfall tends to increase in the SE United States because this region is located to the northwest of the $\mathrm{NASH}$ where winds along the western edge of the NASH transport ample warm and moist air from Gulf of Mexico. The variance of $\mathrm{N}-\mathrm{S}$ movement of the western ridge in the second 30-yr (20-yr) period increased by $47 \%(25 \%)$ using NCEP (ERA-40) at the 1\% (1\%) significance level relative to the first period, corresponding to the enhanced variation of the summer precipitation over the SE United States (Fig. 1). Such negative coefficients of precipitation are not significant in the first period (Figs. 5a and 5c), indicating significantly increased impacts of the NASH on the summer rainfall over the SE United States from the first to the second period.

Are the observed changes of the NASH caused by natural climate variability or anthropogenic forcing? We have examined the relationship between the changes of NASH and other natural decadal variability modes, such as the AMO and the PDO (Fig. 2). The correlation between the AMO (PDO) index and longitude of the western ridge is only $-0.19(0.18)$ and does not pass significance tests. Thus, natural decadal modes do not appear to explain the changes of NASH. We therefore examine the potential impact of anthropogenic forcing on the changes of NASH by comparing the observed trends with modelbased estimates of unforced trends and of the forced changes in the twentieth-century experiments following Santer et al. (2006) and Li et al. (2008).

Figures $6 \mathrm{a}$ and $6 \mathrm{~b}$ illustrate the fractional distribution of the NASH intensity trends and the western ridge trends in the preindustrial (PICNTRL, $50 \mathrm{yr}$ ), the twentieth-century (20C3M, 1950-99), and the twenty-first-century simulations (A1B, 2050-99) obtained from all the 23 CMIP3 models. In the twentieth century, about $58 \%$ of models show an increase of the NASH center's intensity compared to the distribution (20\%) in the PICNTRL simulations (Fig. 6a). The percentage reaches $100 \%$ in the twenty-first century (Fig. 6a). More than $60 \%$ of the models demonstrate a higher rate of the increase in the center's intensity (greater than 1.5 gpm decade ${ }^{-1}$; Fig. 6a). The western boundary of the NASH further expands with the increase of the center's intensity in both the $20 \mathrm{C} 3 \mathrm{M}$ and A1B simulations. In the twenty-first century with the increase of greenhouse gases, all models suggest westward expansions (Fig. 6b) compared to $65 \%$ models in the twentieth century, indicating a more important role of the NASH in the SE U.S. climate. On the contrary, the PICNTRL simulations indicate a majority of the models without trends or showing slight eastward movement of the NASH west edge, instead of observed westward movement (Fig. 6b). Figure $6 \mathrm{c}$ demonstrates the trend of standard deviation in $\mathrm{N}-\mathrm{S}$ change of the western ridge in the preindustrial (PICNTRL), the twentieth $(20 \mathrm{C} 3 \mathrm{M})$, and the twenty-first (A1B) centuries. In the twentieth century, the enhanced meridional movement of the NASH western ridge has been captured by about $30 \%$ models, similar to the percentage suggested by the PICNTRL simulations. However, the NASH is located relatively 
a) NCEP (1948-1977)

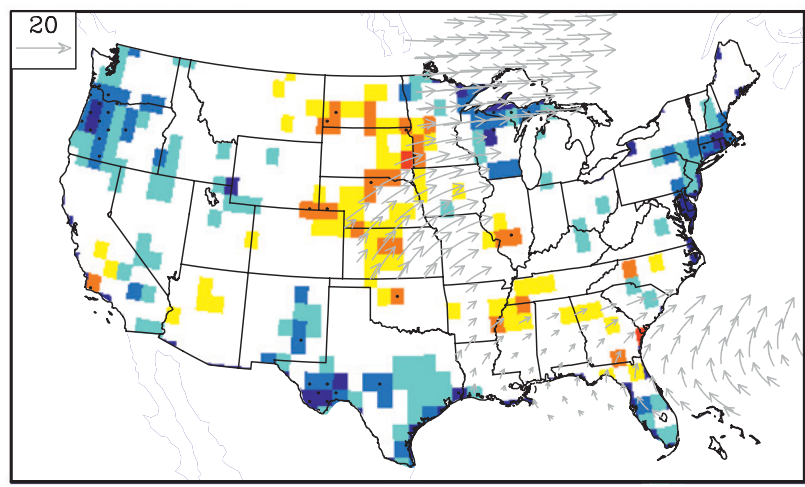

b) NCEP (1978-2007)

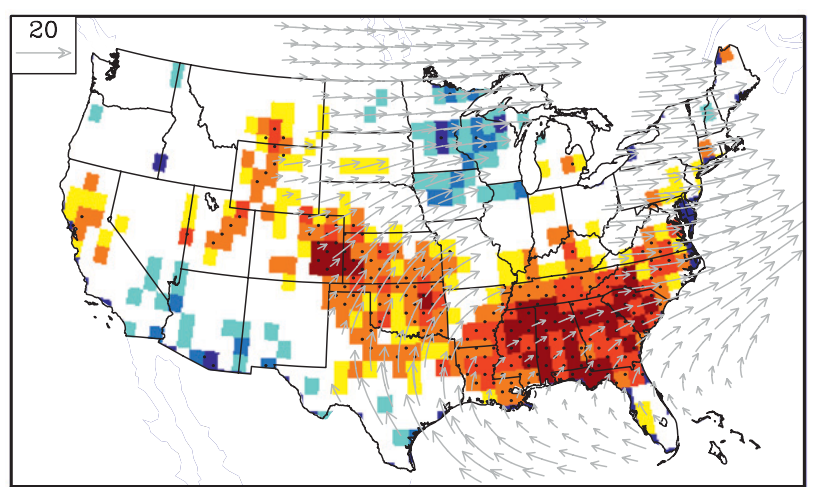

c) ERA-40 (1958-1977)

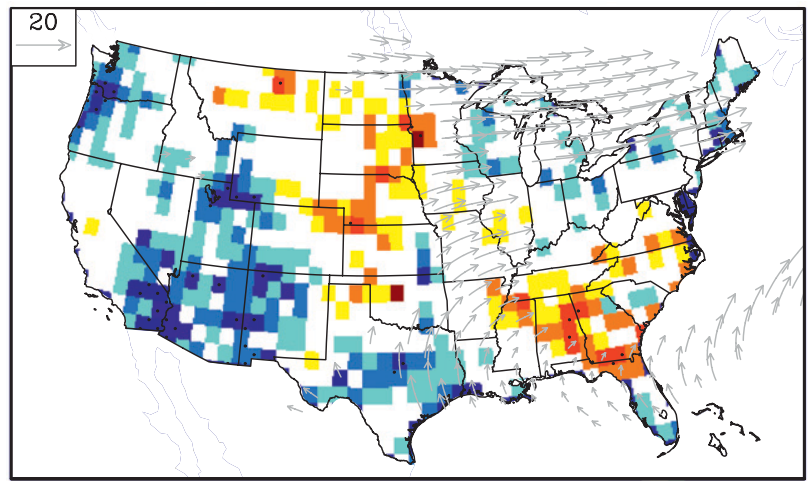

d) ERA-40 (1978-2002)

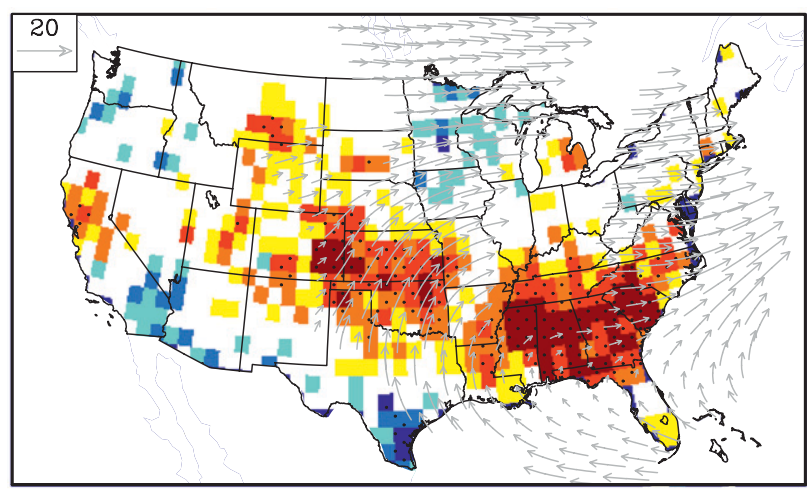

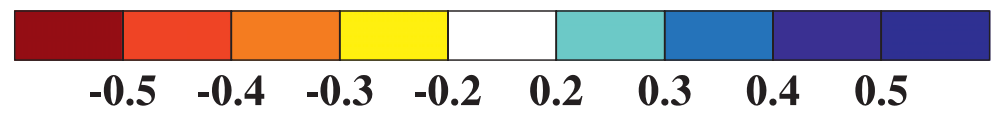

FIG. 5. Linear regression of precipitation (shaded, $\mathrm{mm} \mathrm{day}^{-1}$ ) and moisture flux (vectors, $\mathrm{Kg} \mathrm{m} \mathrm{s}^{-1}$, only grid points passing the $95 \%$ confidence level are plotted) against the latitude of the NASH western ridge during (a) the first 30-yr period (1948-77), (b) the second 30-yr period (1978-2007) in NCEP, and (c) first period (1958-77) and (d) the second period (1978-2002) in ERA-40, respectively. Stippling denotes areas where precipitation is statistically significant at the $95 \%$ level.

eastward from the continental United States in the PICNTRL simulations (Fig. 6b); thus, its impact on rainfall of the SE United States is weaker than observed. The enhanced $\mathrm{N}-\mathrm{S}$ variations of the western ridge are more apparent in the twenty-first century, with $70 \%$ of models showing an increased trend of standard deviations (Fig. 6c). The summer precipitation has also indicated an enhancement of variability. Figure $6 \mathrm{~d}$ shows the difference of the precipitation variance between the twenty-first and the twentieth centuries. About $70 \%$ of the models show an enhancement of rainfall variability in the SE United States with the increase of greenhouse gases in the twenty-first century, suggesting an increase of the summer precipitation variability associated with the westward extension of the NASH and increase of the NASH's impact.

\section{Conclusions and discussion}

In recent decades, enhanced variability of the summer precipitation has been observed over the southeastern United States (Wang et al. 2010). Our results show that such an enhancement of rainfall variability is closely related to the changes of the NASH. Using 850 -hPa geopotential height data from NCEP, ERA-40 reanalysis, and CMIP3 models used for the IPCC AR4, we analyzed the intensity and western ridge movement of the NASH in recent summers. Our results suggest that the NASH has moved westward with the increase of its center's intensity during the period since 1978 compared to the period before 1978 in both NCEP and ERA-40 reanalysis. The westward extension of the subtropical high's ridge 
(a)

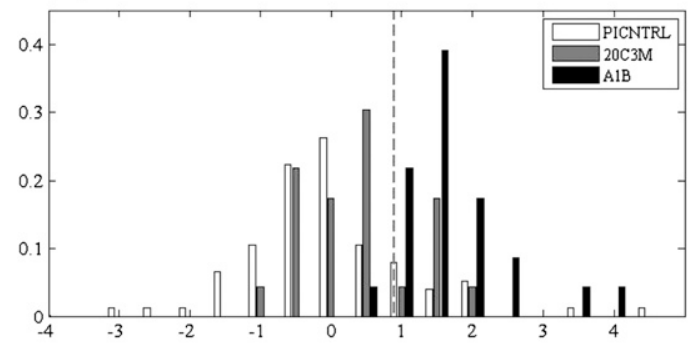

(c)

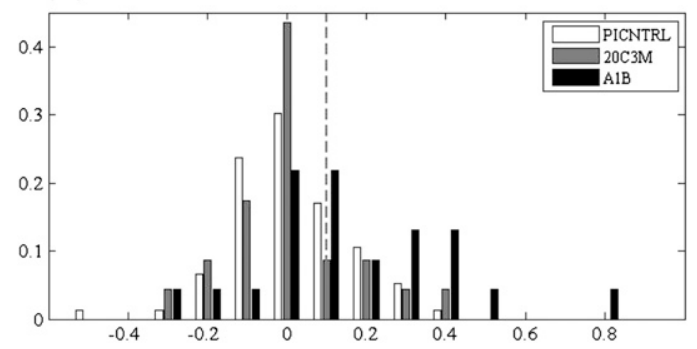

(b)

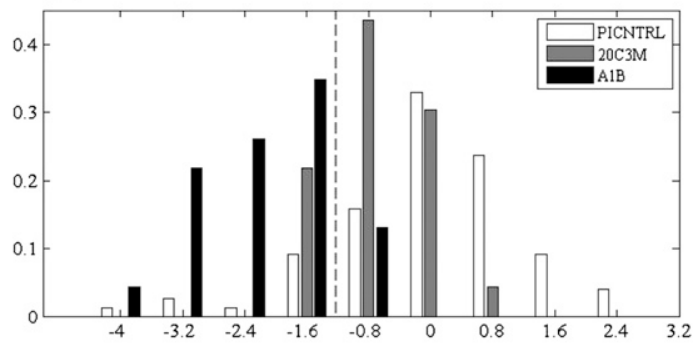

(d)

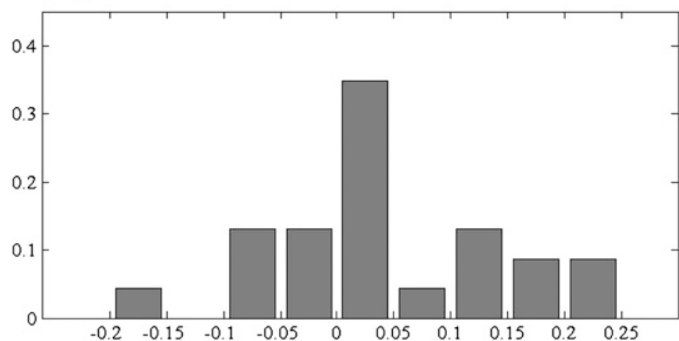

FIG. 6. Distributions of (a) the trend of the NASH center's intensity (gpm decade ${ }^{-1}$ ); (b) the trend of westward extension of the NASH western ridge $\left({ }^{\circ}\right.$ decade $\left.^{-1}\right)$; (c) the trend of the standard deviation of the western ridge's latitude $\left({ }^{\circ}\right.$ decade $\left.^{-1}\right)$ in the twenty-first-century simulation (A1B, black) compared to those of the twentieth century (20C3M, gray) and pre-industry simulations (PICNTRL, white); and (d) the differences in the standard deviation of the SE U.S. precipitation $\left(\mathrm{mm} \mathrm{day}^{-1}\right)$ between A1B and 20C3M obtained from the 23 AR4 models. The bars in (a)-(c) show the fractional distribution of trends obtained from the three simulations, and observed trends obtained from the NCEP and ERA-40 are shown as dashed lines. The $y$ axis is the fraction of the occurrence of each bin relative to the total sample size.

enhances the influence of the high system on the SE U.S. precipitation through the north-south displacement of the western ridge in the period after 1978. Our results indicated that the NASH has significant trends of the increased center's intensity and westward movement, whereas the N-S movement enhanced in the three recent decades. The different changes/variations between the ridge's meridional movement and the center's intensity as well as the ridge's zonal movement suggest that other factors such as local SST anomalies and midlatitude wave activities need to be considered besides the center's intensity of the NASH.

Our attribution analysis suggests that global warming seems to be contributing to the changes of the NASH. The physical processes that control the changes of the NASH are complex, including monsoon heating in remote areas (Ting 1994; Chen et al. 2001; Rodwell and Hoskins 2001), heating contrasts between the subtropical continents and adjacent oceans (Wu and Liu 2003; Miyasaki and Nakamura 2005), local air-sea interaction (Seager et al. 2003), and shifts in the atmospheric mean circulation (Davis et al. 1997). How global warming influences these processes needs to be investigated in future.

Our analysis of the IPCC AR4 models suggests that the NASH system will likely intensify, expand, and move farther westward in the twenty-first century with the increase of $\mathrm{CO}_{2}$, indicating increased likelihoods of both extreme rainfall events and droughts over the SE United States in the future.

Acknowledgments. We thank the international modeling groups for providing their data for analysis, the Program for Climate Model Diagnosis and Intercomparison (PCMDI) for collecting and archiving the model data, the JSC/CLIVAR Working Group on Coupled Modeling (WGCM) and their Coupled Model Intercomparison Project (CMIP) and Climate Simulation Panel for organizing the model data analysis activity, and the IPCC WG1 TSU for technical support. The IPCC Data Archive at Lawrence Livermore National Laboratory is supported by the Office of Science, U.S. Department of Energy. We also thank Drs. Paul Baker and Song S. Qian for insightful discussion, Dr. Tianjun Zhou and two anonymous reviewers for helpful comments, Dr. Muhammad Shaikh for graphic help, and Mr. John Trostel for editorial assistance. This work is supported by the startup funds from Duke University, the NOAA Climate Prediction Program for Americas (OAROGP-2006-2000116, NA10OAR4310157). Yi Deng is supported by NASA Energy and Water Cycle Study (NEWS) under Grant NNX09AJ36G. 


\section{REFERENCES}

Chan, S. C., and V. Misra, 2010: A diagnosis of the 1979-2005 extreme rainfall events in the southeastern United States with isentropic moisture tracing. Mon. Wea. Rev., 138, 1172-1185.

Chen, P., M. P. Hoerling, and R. M. Dole, 2001: The origin of the subtropical anticyclones. J. Atmos. Sci., 58, 1827-1835.

Davis, R. E., B. P. Hayden, D. A. Gay, W. L. Phillips, and G. V. Jones, 1997: The North Atlantic subtropical anticyclone. J. Climate, 10, 728-744.

Elsner, J. B., and A. A. Tsonis, 1993: Complexity and predictability of hourly precipitation. J. Atmos. Sci., 50, 400-405.

Kalnay, E., and Coauthors, 1996: The NCEP/NCAR 40-Year Reanalysis Project. Bull. Amer. Meteor. Soc., 77, 437-471.

Katz, R. W., M. B. Parlange, and C. Tebaldi, 2003: Stochastic modeling of the effects of large-scale circulation on daily weather in the southeastern U.S. Climatic Change, 60, 189-216.

Koster, R. D., and Coauthors, 2004: Regions of strong coupling between soil moisture and precipitation. Science, 305, 1138-1140.

Kushnir, Y., R. Seager, M. Ting, N. Naik, and J. Nakamura, 2010: Mechanisms of tropical Atlantic SST influence on North American precipitation variability. J. Climate, 23, 5610-5628.

Li, W. H., R. Fu, I. Robinson, J. Negrón, and K. Fernandes, 2008: Observed change of the standardized precipitation index, its potential cause and implications to future climate change in the Amazon region. Philos. Trans. Roy. Soc., B363,1767-1772.

Liu, K., and M. L. Fearn, 2000: Reconstruction of prehistoric landfall frequencies of catastrophic hurricanes in northwestern Florida from Lake Sediment records. Quat. Res., 54, 238-245.

Liu, Y. M., and G. X. Wu, 2004: Progress in the study on the formation of the summertime subtropical anticyclone. Adv. Atmos. Sci., 21, 322-342.

Miyasaki, T., and H. Nakamura, 2005: Structure and formation mechanisms of the Northern Hemisphere summertime subtropical highs. J. Climate, 18, 5046-5065.

Nakicenovic, N., and Coauthors, Eds., 2000: Special Report on Emissions Scenarios. Cambridge University Press, 612 pp.

Riha, S. J., D. S. Wilks, and P. Simoens, 1996: Impact of temperature and precipitation variability on crop model predictions. Climatic Change, 32, 293-311.

Rodwell, M. R., and B. J. Hoskins, 2001: Subtropical anticyclones and summer monsoon. J. Climate, 14, 3192-3211.

Santer, B. D., and Coauthors, 2006: Forced and unforced ocean temperature changes in Atlantic and Pacific tropical cyclogenesis regions. Proc. Natl. Acad. Sci. USA, 103, $13905-$ 13910.

Schubert, S., and Coauthors, 2009: A U.S. CLIVAR Project to assess and compare the responses of global climate models to drought-related SST forcing patterns: Overview and results. J. Climate, 22, 5251-5272.

Seager, R., R. Murtugudde, N. Naik, A. Clement, N. Gordon, and J. Miller, 2003: Air-sea interaction and seasonal cycle of the subtropical anticyclones. J. Climate, 16, 1948-1966.

Sui, C.-H., P.-H. Chung, and T. Li, 2007: Interannual and interdecadal variability of the summertime western north Pacific subtropical high. Geophys. Res. Lett., 34, L11701, doi:10.1029/ 2006GL029204.

Ting, M. F., 1994: Maintenance of northern summer stationary waves in a GCM. J. Atmos. Sci., 51, 3268-3308.

Uppala, S. M., and Coauthors, 2005: The ERA-40 Re-Analysis. Quart. J. Roy. Meteor. Soc., 131, 2961-3012.

Wang, C., and D. B. Enfield, 2001: The tropical western hemisphere warm pool. Geophys. Res. Lett., 28, 1635-1638.

Wang, H., R. Fu, A. Kumar, and W. H. Li, 2010: Intensification of summer rainfall variability in the southeastern United States during recent decades. J. Hydrometeor., 11, 10071018.

Wehner, M. F., 2004: Predicted twenty-first-century changes in seasonal extreme precipitation events in the parallel climate model. J. Climate, 17, 4281-4290.

Wu, G., and Y. Liu, 2003: Summertime quadruplet heating pattern in the subtropics and the associated atmospheric circulation. Geophys. Res. Lett., 30, 1201, doi:10.1029/2002GL016209.

Wu, L., and Z. Liu, 2005: North Atlantic decadal variability: Airsea coupling, oceanic memory, and potential Northern Hemisphere resonance. J. Climate, 18, 331-349.

Wu, W., R. E. Dickinson, H. Wang, Y. Liu, and M. Shaikh, 2007: Covariabilities of spring soil moisture and summertime United States precipitation in a climate simulation. Int. J. Climatol., 27, 429-438.

Zhou, T., and Coauthors, 2009: Why the western Pacific subtropical high has extended westward since the late 1970s. J. Climate, 22, 2199-2215.

Zishka, K. M., and P. J. Smith, 1980: The climatology of cyclones and anticyclones over North America and surrounding ocean environs for January and July, 1950-77. Mon. Wea. Rev., 108, 387-401. 